\title{
Global Self-Esteem and Self-Efficacy Correlates: Relation of Academic Achievement and Self-Esteem among Emirati Students
}

\author{
Ernest Afari \\ Lecturer, Advanced University Placement Department \\ The Petroleum Institute, Abu Dhabi, United Arab Emirates \\ E-mail: eafari@pi.ac.ae \\ Graeme Ward \\ Director, Advanced University Placement Department \\ The Petroleum Institute, Abu Dhabi, United Arab Emirates \\ E-mail: gward@pi.ac.ae \\ Myint Swe Khine \\ Associate Professor and Head, Graduate Programs and Research Division \\ Bahrain Teachers College, University of Bahrain, Manama, Kingdom of Bahrain \\ E-mail: m.khine@curtin.edu.au
}

Received: September 22, 2011

Accepted: October 19, 2011 Published: April 1, 2012

doi:10.5539/ies.v5n2p49

URL: http://dx.doi.org/10.5539/ies.v5n2p49

\begin{abstract}
We investigated the relationships between global self-esteem, academic self-efficacy and academic performance among a sample of 255 college students in the United Arab Emirates. The widely used Rosenberg's Self-Esteem Scale (RSES; Rosenberg, 1965) and an academic self-efficacy scale, modified from (Jinks and Morgan, 1999) were used to assess student's self-esteem and their academic self-efficacy. Each student's average grade for the mid-semester and final semester was used as the performance measure. Confirmatory factor analyses using Analysis of Moment Structures (AMOS) version 18 performed on the scores of the RSES revealed two factors (positive and negative self-esteem) as hypothesized. Correlated results indicated significant relationships between global self-esteem and academic self-efficacy. Also academic achievement was associated with having high academic self-efficacy.
\end{abstract}

Keywords: Global self-esteem, Self-efficacy, Rosenberg self-esteem scale, Academic achievement

\section{Introduction}

An individual's self-esteem is one of the major factors in self-image or self-concepts and considered to be an important determinant in human behaviour. As such self-esteem has been conceptualised and examined in a variety of ways in the educational, sociological and psychological contexts. Self-esteem according to Ferkany (2008) is "how a person feels about him or herself, good or bad, and as manifested in a variety of ways, for example, in pride or shame, but especially in self-confidence". Possession of high self-esteem has positive behavioural benefits. These include independence, responsibility taking, and toleration of frustration, resistant to peer pressure, willingness to attempt new tasks and challenges, ability to handle positive and negative emotions, and willingness to offer assistance to others (Ferkany, 2008).

Self-esteem can influence various aspects of human behaviour including the level of aspiration, learning and delinquency. In education, self-esteem has been considered as one of the most important factors in determining success and failure in schools. Conversely, there are negative aspects of self-esteem that can cause undesirable effects on behaviours. Donnellan, Trzesniewski, Robins, Moffitt and Caspi (2005) noted that individuals with low self-esteem are prone to real-world externalizing problems such as delinquency and antisocial behaviour. In their studies it was found that self-esteem was consistently negatively correlated with delinquency regardless of the type 
of questionnaires they used. This study sets out to explore the global self-esteem and academic self-efficacy of Emirati students.

\subsection{The Rosenberg Self-Esteem Scale}

Self-esteem has been accessed by using self-report questionnaires. The Rosenberg Self-Esteem Scale (RSES) (Rosenberg, 1979) is the most widely used, validated and documented in the academic literature. The scale is designed to measure the person's self-esteem understood as overall evaluation of his or her worthiness as human being. The scale contains the items that measures self-worth and self-efficacy.

The RSES is simple, ten-item self-report instrument with convincing face validity and easy to administer. A significant number of studies have been conducted internationally using Rosenberg Self-esteem Scale in the past two decades. Some studies were conducted to validate the instrument when it was translated into foreign languages and some are correlation studies and attempt to find out the mediation effects of the construct with other personality variables. Although the scale is assumed to be unidimensional, factor and structural analysis revealed different results in different contexts.

Ang, Neubronner, Oh and Leong (2006) administered the Rosenberg's Self-Esteem Scale to 153 students in Singapore. The purpose of the experiment was to validate the instrument and to test the relationship between self-esteem and other personality factors. The confirmatory factor analysis revealed two factors (positive and negative self-esteem). The results from the multiple regression analyses showed that positive self-esteem significantly predicted students' mastery goal orientation and academic self-efficacy scores. On the other hand negative self-esteem significantly predicted students' disruptive behaviours. The authors concluded that the Rosenberg's scale in this context produced two factors and contradicted the unidirectionality of global self-esteem in previous research taken placed in other countries.

\subsection{Self-Esteem and Its Associations with Other Variables}

Self-esteem is found to be associated with some of the personality variables. Zhang and Postiglione (2001) explored the relationships between self-esteem, thinking styles, and socio-economic status in Hong Kong. The study was conducted with 694 students in a university in Hong Kong using Thinking Style Inventory (Sternberg \& Wagner, 1992) and RSES for self-esteem measures. They found that those who are from higher socio-economic status tend to have higher self-esteem. They also found a relation between the thinking styles and socio-economic status.

Arising from the research of Piaget (1955), Kelly (1963) and later von Glasersfield (1995) (among many others), there is a significant body of evidence and opinion that knowledge and understanding is constructed from prior (learner) knowledge and experience. While there is still debate as to how this process of construction occurs and as to what are optimal conditions for learner construction, it is agreed that learning is not a passive endeavor and that the process of learning is influenced not only by prior knowledge - as facts or data - but prior knowledge and experience, including a learner's self evaluation of success or failure.

Following on from this, it can be argued that it is within the social dimension that an individual's self esteem is constructed, in that esteem is an act of comparison with others from within the same social group or learning culture, and it is upon reflection of one's performance within each learning culture that one determines and evaluates one's performance and albeit confidence and or (self) worth within this social frame of reference.

Arguably, one's self esteem is a relevant outcome of the process of evaluating one's performance over a variety of applications and the subsequent learning experience associated with that. It can be argued that if a learner has experienced success and its related positive connotations, then it is to be expected that that learner will have enhanced confidence and an expectation of further success - their esteem levels would be expected to be high. If, however, a learner is constantly failing to meet their own or their learning community's expectations one would expect them to lack confidence within the given situation and that they would possibly exhibit symptoms related to low self esteem.

More than three decades ago, Bandura (1977) theorised that a potent influence on student behaviour is the beliefs that they hold about their capabilities. According to social cognitive theory, students are more likely to have an incentive to learn if they believe that they can produce the desired outcomes (Bandura, 1986). Hence, self-efficacy beliefs are powerful predictors of the choices that students make, the effort that they expend and their persistence in facing difficulties. Furthermore, aside from task value, a major motivational component of expectancy-value theory is self-efficacy beliefs.

Bassi, Steca, Fave and Caprara (2007) has noted that in academic settings, students' perceived self-efficacy affects their academic interest and motivation, management of academic stress. Researchers have been successful in demonstrating that self-efficacy beliefs are positively related to and influence academic achievement and that these 
beliefs mediate the effect of skills, previous experience, mental ability, or other self-beliefs on subsequent achievement (Pajares \& Schunk, 2001).

One premise of our study was that student self-efficacy beliefs regarding competence could have important implications for improving student outcomes (Lorsbach \& Jinks, 1999; Aldridge \& Fraser, 2008). Our study investigated whether association exists between students' self-efficacy and their academic achievements.

\section{Objectives}

The objectives of the study reported in this paper were to:

i. Test the validity and reliability of the self-esteem questionnaire when translated into Arabic and administered to college students in the United Arab Emirates.

ii. Explore if a relationship exists between the students' general self-esteem and academic self-efficacy.

iii. Examine associations between the self-esteem, academic self-efficacy and academic achievements.

\section{The Experiment}

\subsection{Participants and Procedure}

The participants for this study were 255 first year mathematics students who are enrolled at one of the tertiary learning institutions in the United Arab Emirates. Among the participants 181 (71\%) were male and $74(29 \%)$ were female. The students' age range from 17-21 with the mean age of 18.5 . About $90 \%$ of the students were UAE nationals and the rest were from the neighbouring Arab countries. The questionnaire was administered at the middle of the semester. Participants completed the questionnaires in their classrooms during normal school hours. One of researchers distributed the questionnaire, explained the procedure, and answered students' clarifications. The students took approximately 20 minutes to complete the questionnaires and participation was voluntary.

\subsection{Measurements}

\subsubsection{Global Self-esteem}

Global self-esteem was measured by the Rosenberg's Self-esteem Scale (RSES) (Rosenberg, 1965). The 10-item scale was translated into Arabic and tested for face validity. Bi-lingual version (English and Arabic) of the questionnaire was used in this study. The participants completed the scale by indicating their agreement with each of the 10 items on a 4-point scale (4= strongly agree through to $1=$ strongly disagree). The sample items read "On the whole I am satisfied with myself" and "I certainly feel useless at times". The scores for negatively worded items were reversed and the self-esteem score was obtained by summing up all the scores. The total score can be ranged from 10-40. Higher scores reflected higher self-esteem. In our study, the Cronbach alpha reliability was 0.80 and considered an internally reliable scale.

\subsubsection{Academic Self-efficacy}

The eight-item Academic self-efficacy was based on Jinks and Morgan (1999) Student Efficacy Scale (MJSES). This questionnaire was originally developed in English. Because all of the participants involved in our study spoke English as a second language, an Arabic translation was created to ensure that they were able to understand the items. The response alternatives for each item are Almost Always, Often, Sometimes, Seldom and Almost Never. Only items with a positive scoring direction were also used in the Academic Efficacy scale. Examples of items are "I find it easy to get good grades in mathematics" and "I feel that I am an intelligent student". In our study, the Cronbach alpha reliability for the academic self-efficacy was 0.89 and considered an internally reliable scale.

\subsubsection{Academic Achievement}

Each student average grade from the mid semester and final semester was used as the academic achievement measure. Academic achievement scores are from their average mid semester grade and end of semester grade. The grades for the mid semester included the following: Test $1-10 \%$, midterm exams $-20 \%$, quizzes $-15 \%$, homework $-5 \%$, class participation $5 \%$. The final grade was comprehensive; it covered the whole semester work. This includes the following: Test $1-10 \%$, midterm exams $-20 \%$, Test $2-10 \%$, quizzes $-15 \%$, homework $-5 \%$, class participation $5 \%$, and final exam $-30 \%$. Higher scores reflected higher academic achievement.

\section{Data Analysis}

Data were analysed by means of confirmatory factor analysis (CFA) and structural equation modelling (SEM) using AMOS 18 program. SEM is a statistical methodology that takes a confirmatory approach to the analysis (Byrne, 2010). In this approach a hypothesized model of relations between variables is tested statistically to determine the extent to which it is consistent with the data, which is referred to as the goodness of fit. If the goodness of fit is 
adequate it supports the plausibility of the relations among variables (Skaalvik \& Skaalvik, 2010).

We used four indicators of fit to assess the models tested, including the chi-square goodness-of-fit test (Jöreskog, 1977), the comparative fit index (CFI; Bentler, 1990), the root mean square error of approximation (RMSEA; Brown \& Cudeck, 1993). For the CFI and IFI indices, values greater than 0.90 are typically considered acceptable and values greater than 0.95 indicate a good fit to the data (Bollen, 1989; Byrne, 2010; Hu \& Bentler, 1999). For well specified models, an RMSEA of less than 0.06 is considered to have a good model fit (Hu \& Bentler, 1999).

\section{Results}

\subsection{The Rosenberg's Self-Esteem Scale (RSES)}

In our study we used confirmatory factor analysis (CFA) to examine two models from the ten-item RSES using AMOS version 18. Model 1 defined one primary factor only and tested if the 10-item RSES could be treated as a one-dimensional for which Marsh, 1996 and Pullmann and Allik (2000) found evidence in their studies. Model 2 tested a two-factor model based on the positively and negatively worded ten-item RSES found in a study by Ang et al. 2006.

The first confirmatory factor analysis explored the one-factor structure of the RSES. The fit indices for this one-factor model are given in Table 1, from which it can be seen that this model had an acceptable fit to the data $\left(\chi^{2}=80.10, \mathrm{CFI}=0.90, \mathrm{IFI}=0.91, \mathrm{RMSEA}=0.071\right)$. Looking for a better-fitting model, resulted in the inclusion of one error covariances (namely, between Items SE1 and SE2). This gave us a model with good fit indices (CFI = 0.95 , IFI $=0.95$, RMSEA $=0.051$ ). These errors convariances are explicable in relation to content: both items 1 and 2 refer to the beliefs respondents have about themselves. Clearly, there appears to be an overlap of content between these two items.

Model 2 was the two-factor structure (positively and negatively worded item RSES). The fit indices for this two-factor model are also given in Table 1, from which it can be seen that this model also had an acceptable fit to the data $\left(\chi^{2}=77.86, \mathrm{CFI}=0.91\right.$, IFI $=0.91$, RMSEA $\left.=0.071\right)$. Looking for a better-fitting model, resulted in the inclusion of one error covariance (namely, between Items SE1 and SE6). This gave us a model with good fit indices $(\mathrm{CFI}=0.96, \mathrm{IFI}=0.96, \mathrm{RMSEA}=0.045)$. This error covariance which has to be included is almost the same for the one-factor model. Taking into accounts that the fit indices ( $\chi^{2}$, CFI, IFI, and RMSEA) for the two-factor model exceeded that of the one-factor model, and that the correlation between positive and negative self-esteem factors $(\mathrm{r}=$ 0.89 ) indicates a strong amount of shared variance between the two factors, it is reasonable to conclude that the two-factor model appears to be a relatively good approximation to the data.

\subsection{Positive and Negative Self-Esteem and Academic Self-Efficacy}

The relationship between positive and negative self-esteem and academic self-efficacy were explored by means of a confirmatory factor analysis. We tested a model specifying three correlated latent variable; positive self-esteem, negative self-esteem and academic self-efficacy (Fig. 1). The model had acceptable fit to the data $\left(\chi^{2}=276.69\right.$, CFI $=$ $0.91, \mathrm{IFI}=0.91$ and RMSEA $=0.07)($ Table 2$)$.

The model for the positive and negative self-esteem and academic self-efficacy was adjusted on the basis of modification indices. We attended to only those modifications which were theoretically defensible; namely, the inclusion of two error covariance (namely, items AE1 and AE6 and items AE3 and AE8, both are items of the academic self-efficacy scale). Items AE1 and AE6, and Items AE3 and AE8 both suggest redundancy due to content overlap. Item AE1 asks if respondent find it easy to get good grades in mathematics, whereas item AE6 asks if respondent feels that they will pass mathematics with ease. Clearly, there appears to be an overlap of content between these items. This resulted in a model with good fit indices $\left(\chi^{2}=226.54, \mathrm{CFI}=0.94\right.$, IFI $=0.94$, RMSEA $=$ 0.05). This error covariance is explicable in relation to content.

The positive self-esteem correlated very strongly with the negative self-esteem $(r=0.93)$. Also the positive self-esteem and the academic self-efficacy was slightly strong $(\mathrm{r}=0.44)$. Both are statistically significant at the $p<.001$ level. But the negative self-esteem and the academic self-efficacy was weakly correlated $(\mathrm{r}=0.21)$ and not statistically significant. This replicate past research which has reported significantly positive impact of self-esteem and academic self-efficacy (Ang et al. 2006; Smith, Walker, Fields, Brookins \& Seay, 1999).

\subsection{Positive and Negative Self-Esteem, Academic Self-Efficacy and Academic Performance}

One of the purposes of our study was to test if associations between the self-esteem, academic self-efficacy and academic achievements exist. These were explored by means of a confirmatory factor analysis. We tested a theoretical model specifying four correlated latent variable; a second order positive self-esteem and negative-self esteem and also an academic self-efficacy and academic achievement. The model had good fit to the data $\left(\chi^{2}\right.$ 
$=282.85, \mathrm{CFI}=0.94, \mathrm{IFI}=0.94$ and RMSEA $=0.05)$ and is displayed graphically in figure 2. The positive self-esteem correlated very strongly with the negative self-esteem $(r=0.93)$. Also the positive self-esteem and the academic self-efficacy was slightly strong $(\mathrm{r}=0.45)$. Both are statistically significant at the $p<.001$ level. But the negative self-esteem and the academic self-efficacy was weakly correlated $(r=0.20)$. The academic achievement and academic self-efficacy also correlated strongly $(\mathrm{r}=0.61)$ and statistically significant at the $p<.001$ level. The academic achievement and positive self-esteem was slightly weakly correlated but not statistically significant. Finally, the academic achievement and negative self-esteem was weakly correlated and not statistically significant. The correlations are displayed in Table 3.

\section{Discussion}

A major contribution to our study is that the widely used Rosenberg's Self-Esteem and an Academic Self-Efficacy scales were translated into the Arabic language and validated. The Rosenberg's Self-Esteem 10-item scale was used to assess student's self-esteem and the Academic Self-Efficacy 8-item scale was used to assess student's academic self-efficacy. For our sample of 255 college students in the United Arab Emirates, the Rosenberg's Self-Esteem Scale and the Academic self-efficacy displayed satisfactorily validity and internal consistency reliability. Dimensionality of the Rosenberg's Self-Esteem scale (RSES) was investigated and confirmatory factor analyses performed on the scores of the RSES revealed two factors (positive and negative self-esteem) as hypothesized. This result add to the growing body of evidence supporting the argument that positive and negative self esteem are distinctly different and that both factors could possibly be measuring substantively distinct dimensions (Ang et al., 2006; Owens, 1994).

The relationship between positive and negative self-esteem and academic self-efficacy explored by means of a confirmatory factor analysis initially revealed an acceptable fit. The model was later adjusted on the basis of modification indices and this resulted in a good fit. The positive self-esteem correlated very strongly with the negative self-esteem, and also the positive self-esteem and the academic self-efficacy was slightly strongly correlated. The results indicate that positive self-esteem significantly predicted student' academic self-efficacy. But the negative self-esteem and the academic self-efficacy was weakly correlated and was not statistically significant.

Past research has indicated that self-esteem is associated with changes in self-efficacy (Dodgson \& Wood, 1998; Lane, Jones \& Steven, 2002). These results also reflect past studies in which positive self-esteem was a significant predictor of self-efficacy scores, while negative self-esteem did not emerge as a significant predictor (Ang et al. 2006).

In our study we also investigated if there are associations between the self-esteem, academic self-efficacy and academic achievements. In accordance with previous research we tested a theoretical model specifying four correlated latent variable; a second order positive self-esteem and negative-self esteem and also an academic self-efficacy and academic achievement. We found academic achievement and academic self-efficacy to be strongly correlated and statistically significant at the $p<.001$ level. The academic achievement and positive self-esteem was slightly weakly correlated but not statistically significant. Also the academic achievement and negative self-esteem was weakly correlated and not statistical significant. This suggests that the relationship between self-esteem and academic achievement is mediated by academic self-efficacy.

A possible interpretation is that students who believe they can perform certain task usually do not experience negative thoughts about their ability to perform a task successfully (Bandura, 1997; Chemers, Hu, \& Garcia, 2001). Our study is consistent with other previous studies that demonstrated that self-efficacy is a powerful variable in predicting student's achievement (Al-Harthy, Was, \& Isaacson, 2010; Andrew, 1998; Bandura, 1993; Barkly, 2006; Paulsen \& Gentry, 1995; Schunk, 1989; Zimmerman, 2000). A study by Paulsen and Gentry (1995) used path analysis to demonstrate that the strongest predictor of performance was self-efficacy. In conclusion, the findings of our study show that among Emirati college students, self-esteem and self- efficacy significantly correlate, and that self-efficacy is related to academic achievement.

An awareness of a learner's past experience in terms of success, failure and subsequently esteem, would be useful information for teachers who are adapting curriculum for the purpose of teaching smaller classes and or individual learners. Such information would complement other information available such as the technical aspects of what and what not the learner currently knows or can do. An assessment of whether the learner overrates or undervalues their own performance and abilities would allow teachers to function in a manner that is encouraging, supportive but realistic.

\section{Conclusion}

This study based on a UAE college adds to a growing body of international literature exploring the widely used 
Rosenberg's Self-Esteem Scale. The findings of our study show that positive self-esteem can lead to high academic self-efficacy, and that academic self-esteem is related to academic achievement. This is consistent with other previous studies that investigated relationships between self-esteem, and academic achievement (Lane, Lane, \& Kyprianou, 2004). Teachers could make use of these relationships in enhancing student's self-esteem. Since self-efficacy and academic achievement are significantly related, changes in one variable are likely to lead to changes in the other. Teachers could facilitate activities that are aimed at promoting students' self-esteem, and also provide more encouragement to students (Zhang \& Postiglione, 2001).

Our study represents one of the first studies conducted in the mathematics classroom in the United Arab Emirates that used the widely used Rosenberg's Self-Esteem and an Academic Self-Efficacy scales which was translated into the Arabic language and validated. However, because our study involved only students from only one college in the United Arab Emirates, the generalisability of the findings could be limited. It is recommended, therefore, that further similar research be carried out to investigate the mediating effects of self-esteem on educational achievement and self-efficacy at the college level in the United Arab Emirates and other countries.

\section{References}

Aldridge, J. M., \& Fraser, B. J. (2008). Outcomes-focused learning environments: Determinants and effects. Rotterdam. The Netherlands: Sense Publishers.

Al-Harthy, I. S., Was, C. A., \& Isaacson, R. M. (2010). Goals, efficacy and metacognitive self-regulation: A path analysis. International Journal of Education, 2, 1-20.

Andrew, S. (1998). Self-efficacy as a predictor of academic performance in science. Journal of Advanced Nursing, 27(3) 596-603. http://dx.doi.org/10.1046/j.1365-2648.1998.00550.x PMid:9543047

Ang, R., Neubronner, M., Oh, S., \& Leong, V. (2006). Dimensionality of rosenberg's self-esteem scale among normal-technical stream students in Singapore. Current Psychology, 25(2), 120-131. http://dx.doi.org/10.1007/s12144-006-1007-3

Bandura, A. (1977). Self-efficacy: Toward a unifying theory of behavioral change. Psychological Review, 84(2), 191-215. http://dx.doi.org/10.1037/0033-295X.84.2.191 PMid:847061

Bandura, A. (1986). Social foundations of thought and action: A social cognitive theory. Englewood Cliffs, NJ: Prentice Hall.

Bandura, A. (1993). Perceived self-efficacy in cognitive development and functioning. Educational Psychologist, 28(2), 117-148. http://dx.doi.org/10.1207/s15326985ep28023

Bandura, A. (1997). Self-efficacy: The exercise of control. New York: Freeman.

Barkley, J. M. (2006). Reading education: Is self-efficacy important? Reading Improvement, 43, 194-210.

Bassi, M., Steca, P., \& Fave, A. D., \& Caprara, G.. V. (2007). Academic self-efficacy beliefs and quality of experience in learning. Journal of Youth Adolescence, 36(3), 301-312. http://dx.doi.org/10.1007/s10964-006-9069-y

Bentler, P. M. (1990). Comparative fit indexes in structural models. Psychological Bulletin, 107(2), 238-246. http://dx.doi.org/10.1037/0033-2909.107.2.238 PMid:2320703

Bollen, K. A. (1989). Structural equations with latent variables. New York: Wiley.

Brown, M. W., \& Cudeck, R. (1993). Alternative ways of assessing model fit. In K. A. Bollen \& J. S. Long (Eds.), Testing structural equation models (pp. 136-162). Newbury park, CA: Sage.

Byrne, B. M. (2010). Structural equation modeling with AMOS: Basic concepts, applications, and programming. New York: Routledge.

Chemers, M. M, Hu, L., \& Garcia, B. F. (2001). Academic self-efficacy and first-year college student performance and adjustment. Journal of Educational Psychology, 93, 55-64. http://dx.doi.org/10.1037/0022-0663.93.1.55

Dodgson, P. G., \& Wood, J. V. (1998). Self-esteem and the cognitive accessibility of strengths and weakness after failure. Journal of Personality and Social Psychology, 75, 178-197. http://dx.doi.org/10.1037/0022-3514.75.1.178 PMid:9686458

Donnellan, M. B., Trzesniewski, K. H., Robins, R. W., Moffitt, T. E., \& Caspi, A. (2005). Low self-esteem is related to aggression, antisocial behaviour, and delinquency. Psychological Science, 16(4), 328-335. http://dx.doi.org/10.1111/j.0956-7976.2005.01535.x PMid:15828981

Ferkany, M. (2008). The educational importance of self-esteem. Journal of Philosophy of Education, 42, 119-132. http://dx.doi.org/10.1111/j.1467-9752.2008.00610.x 
Hu, L-T., \& Bentler, P. M. (1999). Cutoff criteria for fit indexes in covariance structure analysis: Conventional criteria versus new alternatives. Structural Equation Modeling, 6, 1-55. http://dx.doi.org/10.1080/10705519909540118

Jinks, J., \& Morgan, V. (1999). Children's perceived academic self-efficacy: An inventory scale. The Clearing House, 72(4), 224-230. http://dx.doi.org/10.1080/00098659909599398

Jöreskog, K.G. (1977). Structural equation models in the social sciences: Specification, estimation, and testing. In P. R. Krishnaiah (Ed.), Applications of statistics (pp. 265-287). Amsterdam: North-Holland.

Kelly, G. A. (1963). A theory of personality: The psychology of personal constructs. New York: W. W. Norton \& Company.

Lane, A. M., Jones, L., \& Stevens, M. (2002). Coping with failure: The effects of self-esteem and coping on changes in self-efficacy. Journal of Sport Behavior, 25, 331-345.

Lane, J., Lane, A. M., \& Kyprianou, A. (2004). Self-efficacy, self-esteem and impact on academic performance. Social Behaviour and Personality, 32(3), 247-256. http://dx.doi.org/10.2224/sbp.2004.32.3.247

Lorsbach, A., \& Jinks, J. (1999). Self-efficacy theory and learning environment research. Learning Environments Research 2(2), 157-167. http://dx.doi.org/10.1023/A:1009902810926

Marsh, H. W. (1996). Positive and negative global self-esteem: A substantively meaningful distinction or artifactors? Journal of Personality and Social Psychology, 70(4), 810-819. http://dx.doi.org/10.1037/0022-3514.70.4.810 PMid: 8636900

Owens, T. J. (1994). Two dimensions of self-esteem: Reciprocal effects of positive self-worth and self-deprecation on adolescent problems. American Sociological Review, 59, 391-407. http://dx.doi.org/10.2307/2095940

Pajares, F., \& Schunk, D. H. (2001). Self-beliefs and school success: Self-efficacy, self-concept, and school achievement. In R. Riding \& S. Rayner (Eds.), Self- perception (pp. 239-266). London: Ablex Publishing.

Paulsen, M., \& Gentry, J. (1995). Motivation, learning strategies, and academic performance; a study of the college finance classroom. Financial Practice \& Education, 5(1), 78-89.

Piaget, J. (1955). The construction of reality in the child. London: Routledge.

Pullmann, H., \& Allik, J. (2000). The Rosenberg self-esteem scale: Its dimensionality, stability and personality correlates in Estonian. Personality and Individual Differences, 28(4), 701-715. http://dx.doi.org/10.1016/S0191-8869(99)00132-4

Rosenberg, M. (1965). Society and the adolescent self-image. Princeton, NJ: Princeton University Press.

Rosenberg, M. (1979). Conceiving the Self. New York: Basic Book.

Schunk, D. H. (1989). Self-efficacy and achievement behaviors. Educational Psychology Review, 1(3), 173-208. http://dx.doi.org/10.1007/BF01320134

Skaalvik, E. M., \& Skaalvik, S. (2010). Teacher self-efficacy and teacher burnout: A study of relations. Teaching and Teacher Education, 26(4), 1059-1069. http://dx.doi.org/10.1016/j.tate.2009.11.001

Smith, E. P., Walker, K., Fields, L., Brookins, C. C., \& Seay, R. C. (1999). Ethnic identity and its relationship to self-esteem, perceived efficacy, and prosocial attitudes in early adolescence. Journal of Adolescence, 22, 867-880. http://dx.doi.org/10.1006/jado.1999.0281. PMid:10579896

Sternberg, R., \& Wagner, R. (1992). Thinking Style Inventory. Unpublished test. Yale University.

Von Glasersfeld, E. (1995). A constructivist approach to teaching. In L. P. Steffe \& J. Gale (Eds.), Constructivism in Education (pp. 3-15). Hillsdale, NJ: Lawrence Erlbaum Associates.

Zhang, L., \& Postiglione, G. (2001). Thinking styles, self-esteem, and socio-economic status. Personality and Individual Differences, 31(8), 1333-1346. http://dx.doi.org/10.1016/S0191-8869(00)00227-0

Zimmerman, B. J. (2000). Self-efficacy: An essential motive to learn. Contemporary Educational Psychology, 25, 82-91. http://dx.doi.org/10.1006/ceps.1999.1016. PMid:10620383 
Table 1. Summary of Fit indices from Confirmatory Factor Analyses

\begin{tabular}{|l|l|l|l|l|}
\hline Index & 1-Factor model & $\begin{array}{l}\text { 1-Factor model } \\
\text { with1error covariance }\end{array}$ & 2-Factor model & $\begin{array}{l}\text { 2-Factor model with 1 error } \\
\text { covariance }\end{array}$ \\
\hline$\chi^{2}$ & 80.10 & 56.71 & 77.86 & 50.28 \\
\hline df & 35 & 34 & 2.29 & 33 \\
\hline CFI & 0.90 & 0.95 & 0.91 & 0.96 \\
\hline IFI & 0.91 & 0.95 & 0.91 & 0.96 \\
\hline RMSEA & 0.071 & 0.051 & 0.071 & 0.045 \\
\hline
\end{tabular}

Note. CFI = comparative index; IFI = incremental fit index; RMSEA = root-mean-square of error of approximation

Table 2. Summary of Fit indices for CFA for Positive and Negative Self-Esteem and Self-efficacy

\begin{tabular}{|l|l|l|}
\hline Index & 3-Factor model & 3-Factor model with 2 error covariances \\
\hline$\chi^{2}$ & 276.69 & 226.54 \\
\hline $\mathrm{df}$ & 132 & 130 \\
\hline CFI & 0.91 & 0.94 \\
\hline IFI & 0.91 & 0.94 \\
\hline RMSEA & 0.07 & 0.05 \\
\hline
\end{tabular}

Note. $\mathrm{CFI}=$ comparative index; IFI = incremental fit index; RMSEA = root-mean-square of error of approximation

Table 3. Correlations among Self-Esteem, Self-efficacy and Academic Achievement

\begin{tabular}{|ll|lll|}
\hline & & 1 & 2 & 3 \\
\hline 1. & Positive self-esteem & & & \\
\hline 2. & Negative self-esteem & $0.93^{* * *}$ & & \\
\hline 3. Academic self-efficacy & $0.45^{* * *}$ & 0.20 & \\
\hline 4. Achievement & 0.26 & 0.09 & $0.61^{* * *}$ \\
\hline
\end{tabular}

Note.

${ }^{* * *} p<0.001$ 


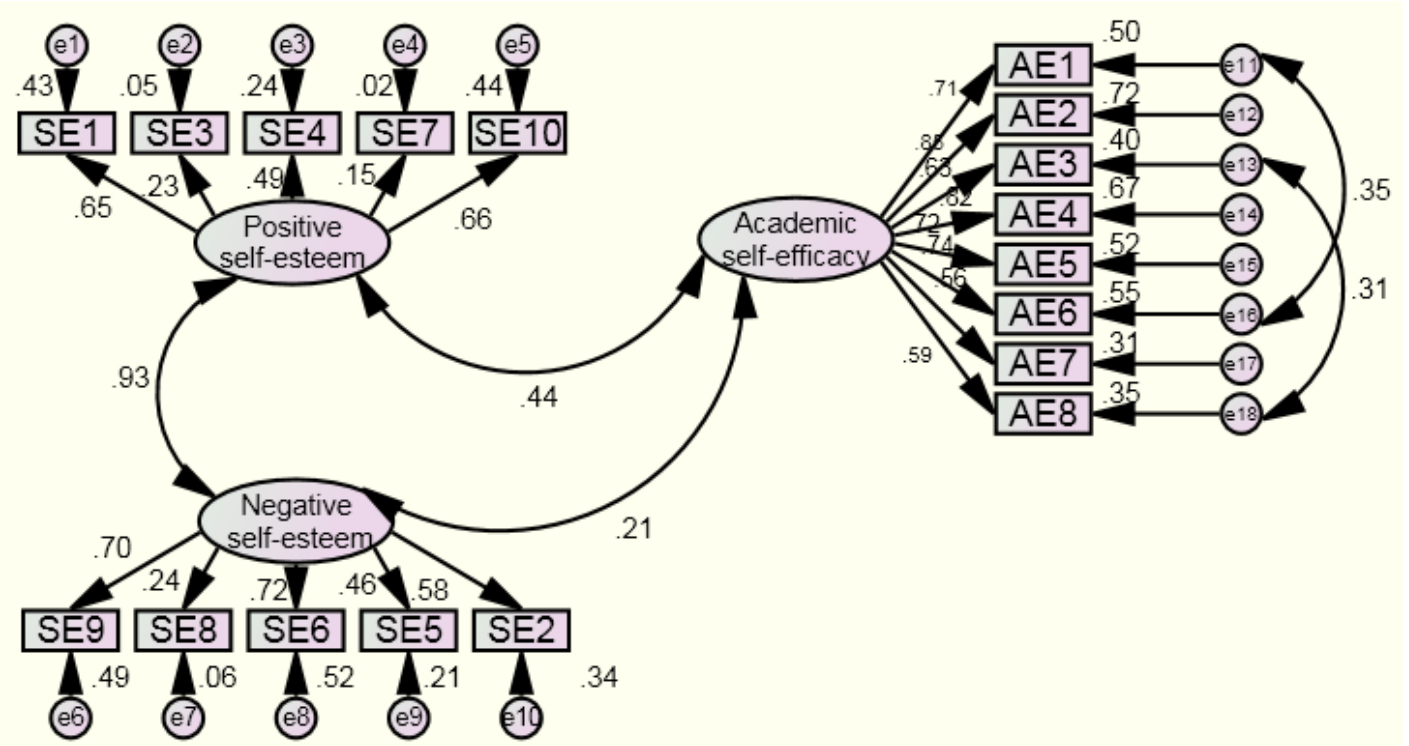

Figure 1. Factor structure for the Positive self-esteem and the Negative Self-Esteem and Academic self-efficacy Scale and their corresponding standardised parameter estimates from the CFA analysis.

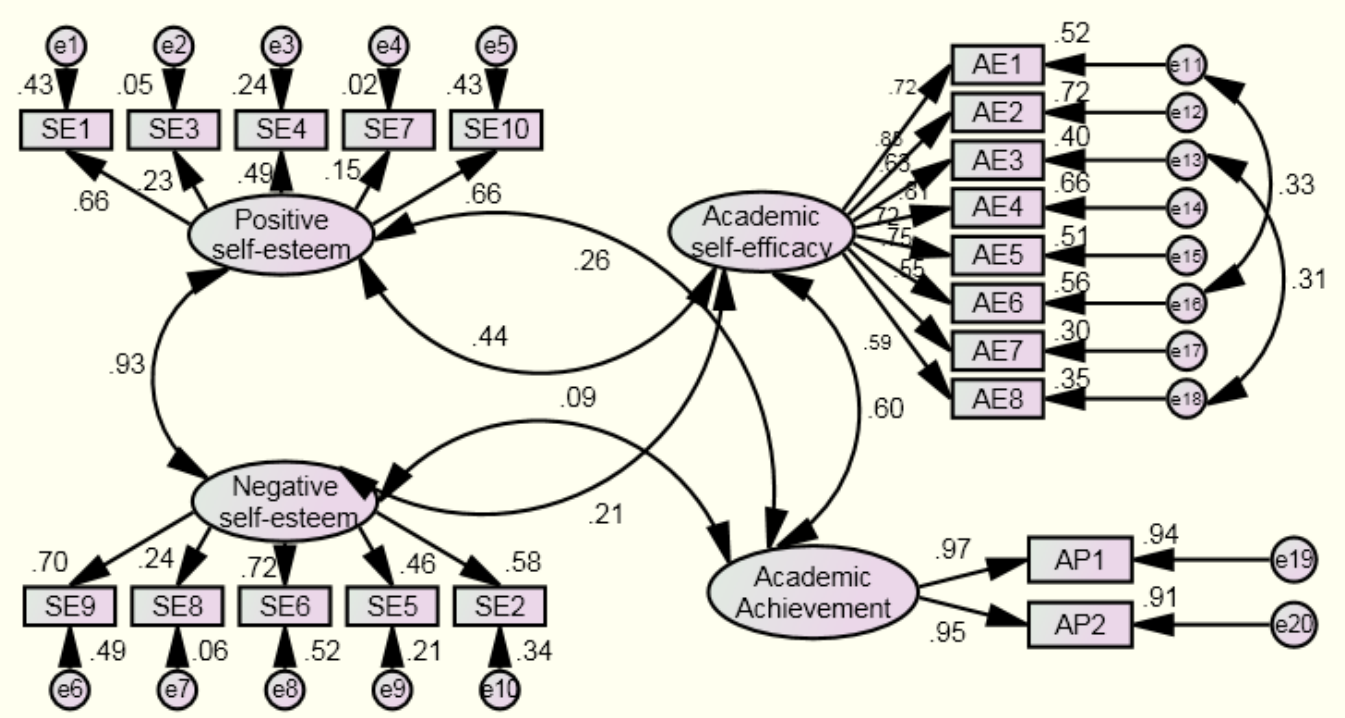

Figure 2. Factor structure for the Positive self-esteem and the negative self-esteem, academic self-efficacy Scale, and academic achievement and their corresponding standardised parameter estimates from the CFA analysis. 